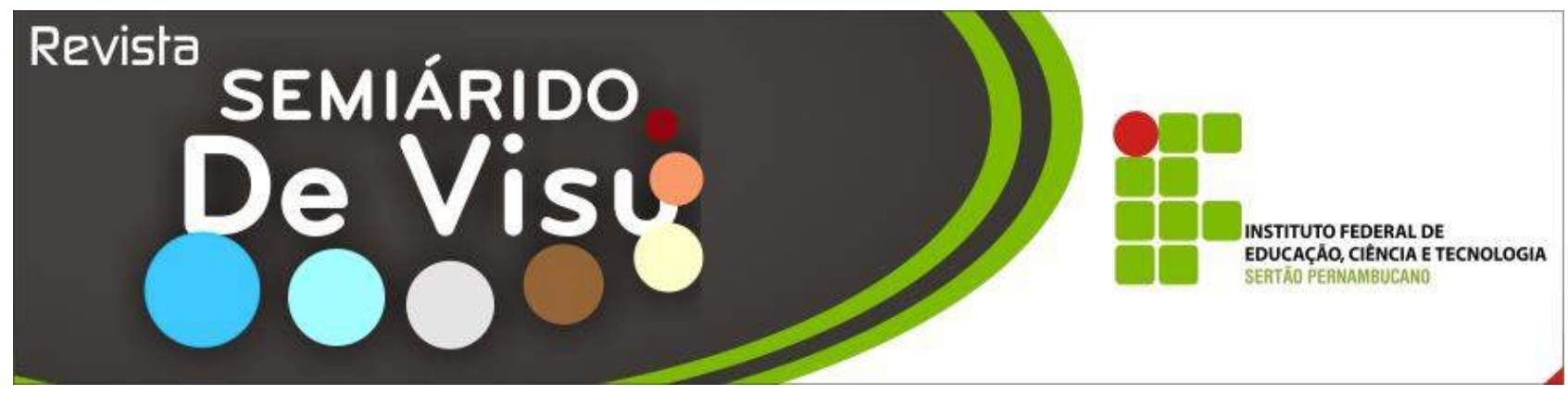

\title{
Enfoques epistemológicos do programa institucional de bolsa de iniciação à docência/PIBID na formação docente
}

\author{
Delza Cristina Guedes Amorim ${ }^{1}$; Josenilton Nunes Vieira ${ }^{2}$
}

\author{
${ }^{1}$ Instituto Federal de Educação Ciência e Tecnologia do Sertão Pernambucano - Campus Petrolina \\ BR 407, Km 08 - Jardim São Paulo - Petrolina/PE/Brasil - CEP 56.314-520 - Telefone: (87) 2101 - 4300 - E-mail: \\ delzacgamorim@gmail.com \\ ${ }^{2}$ Universidade do Estado da Bahia/ UNEB - DCH III - Juazeiro-BA e Autarquia Educacional do Vale do São Francisco / \\ Faculdade de Ciências Aplicadas e Socias de Petrolina - AEVSF/FACAPE - E-mail: josenilton_nunes@uol.com.br
}

\begin{abstract}
RESUMO: Este artigo encontra-se embasado numa pesquisa de mestrado concluída e tem como objetivo refletir sobre a importância dos fundamentos epistemológicos do PIBID na formação docente, enfocando os seus princípios pedagógicos, desenho metodológico e objetivos. Este estudo é relevante por sua dimensão política institucional, pois o PIBID é um programa novo, que faz parte das políticas nacionais para aperfeiçoamento e valorização do magistério, e que tem sido avaliado como um programa de grande repercussão na formação docente. A pesquisa se desenvolveu dentro de uma abordagem qualitativa de inspiração fenomenológica, e, este recorte, apresenta de forma descritiva os resultados baseados na análise dos documentos, estudos avaliativos e relatórios da CAPES/DEB, no período de 2009 a 2014. O aporte teórico fundamenta a discussão da formação e profissionalização docente como campo de interações complexas que promovem o desenvolvimento profissional na construção da identidade e dos saberes da profissão. Conclui que o programa tem mobilizado aspectos formativos nas licenciaturas que podem influenciar mudanças significativas na educação.
\end{abstract}

Palavras-chave: Licenciaturas, profissionalização docente, articulação teoria/prática.

\section{Epistemological approaches from institutional program of initiation scholarship to teaching / PIBID in teacher training}

\begin{abstract}
This article is grounded in a completed master's research and aims to reflect on the importance of the epistemological foundations of PIBID in teacher training, focusing on their pedagogical principles, methodological design and objectives. This study is relevant because of its institutional political dimension, because the PIBID is a new program, which is part of the national policies for improvement and valorization of teaching, and which has been evaluated as a program of great repercussion in teacher training. The research was developed within a qualitative approach of phenomenological inspiration, and this cut presents descriptively the results based on the analysis of documents, evaluation studies and reports from CAPES / DEB, in the period from 2009 to 2014. The theoretical contribution based discussion of training and teacher professionalization as a field of complex interactions that promote professional development in the construction of identity and the teaching profession knowledge. It concludes that the program has mobilized formative aspects in the degrees (graduation) that can influence significant changes in education.
\end{abstract}

Keywords: Degrees (Graduation) teacher professionalization, articulation theory / practice 


\section{Introdução}

A s mudanças no cenário da formação para o magistério por meio das licenciaturas tiveram no Programa Institucional de Bolsa de Iniciação à Docência/PIBID um marco significativo. O programa proposto em 2007 teve sua regulamentação mais detalhada pelo Decreto n. 7219/2010 (BRASIL, 2010) pelo Ministério da Educação no contexto da Política Nacional de Formação de Profissionais do Magistério da Educação Básica.

O PIBID é um dos programas desenvolvidos pela Coordenação de Aperfeiçoamento de Pessoal de Nível Superior/CAPES dentro das políticas para o aperfeiçoamento e valorização da formação de professores para a educação básica. $\mathrm{O}$ programa concede bolsas a alunos de licenciatura participantes de projetos de iniciação à docência, desenvolvidos por Instituições de Educação Superior/IES em parceria com escolas de educação básica da rede pública de ensino. As bolsas se estendem também aos professores coordenadores nas IES, e aos professores supervisores nas escolas de educação básica.

O PIBID, com seus objetivos voltados para a iniciação à docência, tem oportunizado aos licenciandos a vivência na escola e, consequentemente, uma possibilidade de fortalecimento da formação docente mais integrada com a realidade educacional, favorecendo a construção da identidade das licenciaturas nas instituições.

Para participação no Programa, os projetos, submetidos pelas IES e aprovados pela CAPES, devem promover a inserção dos estudantes das licenciaturas no contexto das escolas públicas desde o início da sua formação acadêmica para que desenvolvam atividades didático-pedagógicas, sob a orientação de um docente da licenciatura e de um professor da escola. (BRASIL/CAPES, 2013).

Conforme defende Nóvoa (2009), é preciso passar a formação docente para dentro da profissão, o que permite uma ressignificação da docência em termos mais coerentes com a sua complexidade em relação com a construção da identidade profissional docente.

Na abordagem de Tardif (2014, p.14), ele remete à questão da consciência prática na atuação profissional que faz o professor se sentir satisfeito ou não com o seu trabalho, que faz sentir necessidade de estudar, aprofundar-se.

Pimenta (2012) discute a prática docente inerente à ação pedagógica e questiona o papel da Pedagogia para o professor. A Pedagogia como conhecimento da e para prática deve dotar o professor de uma análise reflexiva sobre sua ação docente.

$\mathrm{O}$ enfoque epistemológico do PIBID aqui apresentado contempla a necessidade da formação inicial perpassar os saberes e fazeres docentes envolvendo os formadores (professores das IES), os licenciandos, os coformadores (professores das escolas) e os estudantes das escolas de educação básica em articulação com as IES.

\section{Material e métodos}

Permeado por uma abordagem qualitativa de inspiração fenomenológica, o recorte deste estudo apresenta de forma descritiva os resultados baseados na análise nos seguintes documentos: Relatório de gestão da CAPES/DEB, referente ao período de 2009-2014, onde são apresentados os princípios pedagógicos e o desenho metodológico do PIBID. A portaria $\mathrm{n}^{\circ} 096 \mathrm{de}$ 2013, que consta os sete objetivos do PIBID, e dados do Censo da Educação básica e superior MEC/INEP, publicados no Anuário da Educação 2015/ TODOS PELA EDUCAÇÃO.

\section{Resultados e discussão}

Serão apresentados a seguir os fundamentos e discussões que abrangem três focos destacados nos documentos: os princípios pedagógicos do PIBID, o desenho metodológico e os objetivos. 
Princípios pedagógicos do PIBID

Conforme relatório de gestão de 2009-2014 da Diretoria de Formação de Professores da Educação Básica/ PIBID,
(CAPES/DEB, 2015, p.65) " [...] os princípios, sobre os quais se constrói o Programa, estão de acordo com estudos de Nóvoa sobre formação e desenvolvimento profissional de professores e são":

Figura 01 - Princípios pedagógicos do PIBID

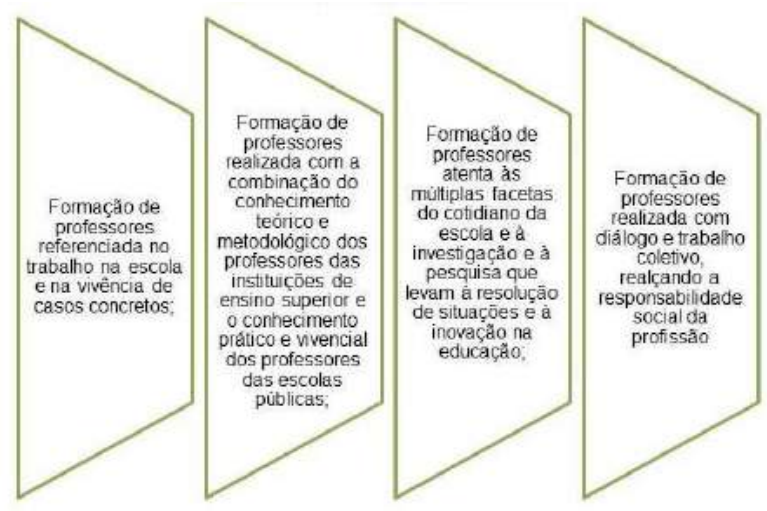

Fonte: Adaptado de CAPES/DEB (2015, p.65).

O PIBID, com seu foco na iniciação à docência, permite uma vivência dentro do processo de formação inicial fundamentada a partir da prática como instrumento de pesquisa, possibilitando a construção de uma visão crítica sobre a escola, os sistemas de ensino e as políticas educacionais, e as condições reais do ambiente escolar. A grande contribuição do PIBID é possibilitar, conforme Melo (2012, p. 35), a construção de sentido aos conteúdos pedagógicos, rompendo com a visão simplista de que algumas disciplinas pedagógicas no currículo darão conta da preparação do professor para sua tarefa tão complexa. Os quatro princípios já apresentados serão discutidos a seguir.

$\mathrm{O}$ primeiro princípio, que se fundamenta no PIBID, é o da formação de professores referenciada no trabalho na escola e na vivência de casos concretos. Nóvoa (2009) chama a atenção para que a formação dos professores seja dentro da profissão, pois, na realidade atual, quem forma o professor nem sempre tem experiência com a docência. Para o autor a contribuição de especialistas, pesquisadores, gestores, tecnólogos, etc, atores de outros segmentos, diminui a carga simbólica dos professores.

Nesse sentido, se, na formação docente, os especialistas são requisitados, mesmo que não tenham experiência docente, implicitamente coloca o exercício da docência em segundo plano e isso tende a promover as famosas receitas teóricas que não valorizam as realidades contextuais e experienciais dos docentes e os saberes destes perdem o valor simbólico citado por Nóvoa (2009).

O mesmo autor ainda sugere transformar a prática em conhecimento profissional docente por meio de: partilha/reflexão/elaboração e reelaboração/teoria e prática, por meio do estudo dos casos, análise das práticas e da ação pedagógica. Assevera ainda que é preciso centrar o desenvolvimento profissional no coração da profissão. $\mathrm{O}$ coração da profissão docente é o trabalho pedagógico. O núcleo do trabalho pedagógico precisa ser repensado. $\mathrm{O}$ arcabouço teórico apenas não é suficiente para entrar no núcleo do trabalho pedagógico. Corroborando com esse pensamento, Imbernón (2010, p. 9) Não podemos separar a
formação do contexto de
trabalho, porque nos
enganaríamos em nosso
discurso. Ou seja, tudo o
que se explica não serve
para todos nem se aplica a
todos os lugares. O 
contexto condicionará as práticas formadoras, bem como sua repercussão nos professores, e, sem dúvida, na inovação e na mudança.

Quando o autor discute a superação da dicotomia formação/contexto de trabalho, pode-se inferir as multirreferencialidades e complexidades de cada cultura escolar em seus respectivos contextos. Entre eles, o que se refere aos aspectos regionais, identidades e territorialidades.

Voltando aos princípios pedagógicos que fundamentam o PIBID, o segundo princípio focalizado é a formação de professores realizada com a combinação do conhecimento teórico e metodológico dos professores das instituições de ensino superior e o conhecimento prático e vivencial dos professores das escolas públicas. Nóvoa (2003), ao discutir as novas disposições no campo da formação de professores, coloca a escola no seu cotidiano, como lugar de formação e não apenas os cursos das Universidades ou promovidos por especialistas renomados, disseminando modismos. Chama a atenção para a reflexão conjunta como uma das disposições dos professores. Nesse sentido, Nóvoa (2003, p.5), ressalta que a Universidade tem o seu papel, mas a escola também.

A Universidade tem um papel importante a desempenhar na formação de professores. Por razões de prestígio, de sustentação científica, de produção cultural. Mas a bagagem essencial de um professor adquire-se na escola, através da experiência e da reflexão sobre a experiência. Esta reflexão não surge do nada, por uma espécie de geração espontânea. Tem regras e métodos próprios.

O PIBID tem esse foco de promover o diálogo do professor das instituições formadoras e os professores da escola. Nóvoa (2009) chama a atenção para a recusa da lógica de individualismo e defende a cultura profissional coletiva por meio da organização de redes e comunidades pedagógicas. Para o autor, essas comunidades referem-se à promoção do trabalho em equipe, o qual cria um novo modelo de profissionalidade que reforça as dimensões coletivas e colaborativas nos projetos educativos da escola.

Essa cultura profissional coletiva tanto no ensino superior, como na educação básica tem sido difícil devido à grande demanda de trabalho docente. O PIBID tem fomentado o diálogo interpares e interinstitucional; porém, em contraponto, também promove outras demandas de trabalho para os envolvidos com o mesmo.

O terceiro princípio focalizado no PIBID diz respeito a uma formação de professores atenta às múltiplas facetas do cotidiano da escola, à investigação e à pesquisa que levam à resolução de situações e à inovação na educação. Nóvoa (2009) defende que a formação de professores deve assumir uma forte componente práxica, centrada na aprendizagem dos alunos e no estudo de casos concretos, tendo como referência o trabalho escolar.

Nesse sentido, destacam-se quatro lições importantes: a primeira, a referência sistemática a casos concretos e o desejo de encontrar soluções que permitam resolvê-los. A segunda, a importância de um conhecimento, que vai para além da teoria e da prática e que possa refletir sobre o seu processo histórico; a terceira, a procura de um conhecimento pertinente, que não é uma mera aplicação prática de uma teoria qualquer, mas que exige sempre um esforço de reelaboração; a quarta, a importância de conceber a formação de professores num contexto de responsabilidade profissional, sugerindo uma atenção constante à necessidade de mudanças e inovação.

Esses casos concretos podem envolver, por exemplo, uma escola sem laboratórios de ciências e informática ou com os mesmos subutilizados; estudantes sem conhecimentos prévios necessários para o aprofundamento dos conteúdos; professores sem a formação específica nas áreas que 
lecionam; alunos com deficiência sem 0 devido atendimento nas suas especificidades. Esses casos e tantos outros são vivenciados pelos licenciandos e promovem a discussão e reflexão.

Em relação ao conhecimento pertinente, refere-se a promover reflexão e discussão sobre o currículo e contextualização, tanto da educação básica quanto da IES. Existe muito conhecimento exigido dos estudantes e reproduzido mecanicamente, que não tem a devida pertinência para o contexto, enquanto outros, que são deixados de lado, deveriam ser abordados.

Conforme Melo (2012, p. 50), os conteúdos a serem trabalhados na escola, assim como os conteúdos específicos dos cursos, precisam ocupar espaço privilegiado no currículo da licenciatura, pois podem contribuir para introduzir uma referência mais direta da prática escolar no processo de formação inicial do professor. Isso significa aproximar a Física, a Matemática e a Química abordadas na academia, dos conteúdos a serem desenvolvidos na escola básica. A atuação do Programa nas IES e nas escolas precisa promover inovação bem refletida, observando as complexidades envolvidas.

O quarto princípio do PIBID, baseado em Nóvoa (2009), é o da formação de professores realizada com diálogo e trabalho coletivo, realçando a responsabilidade social da profissão. A função social da escola como legitimadora do saber precisa de um olhar para os desafios da sociedade no século XXI. $\mathrm{O}$ autor adverte para a necessidade de recontextualizar a escola no seu lugar próprio, valorizando aquilo que é especificamente escolar, deixando para outras instâncias sociais como a família, suas próprias responsabilidades. A escola deve centrar sua missão nas aprendizagens para o futuro e não na missão impossível de regenerar o mundo. A visibilidade social confere prestígio profissional, e os programas de formação precisam atentar para essa nova realidade da profissão docente.

A formação realizada com diálogo e trabalho coletivo objetiva ampliar o espaço formativo para além da sala de aula e do arcabouço teórico. É necessário visualizar a realidade social e dialogando com os diversos segmentos da mesma, entre eles a família, compreendendo as responsabilidades de cada um para que o papel da escola seja compatível com o seu objetivo de potencializar as aprendizagens que são requeridas no presente século.

Recontextualizar, reconstruir é um processo que envolve reflexão, ruptura de paradigmas e, principalmente, uma ação dialógica em virtude da complexidade social que se vive no processo educativo, o que, segundo Imbernón (2010, p. 100-101),

[...]faz com que a profissão
docente e sua formação se
tornem, der maneira
correspondente, mais
complexas, superadoras do
interesse estritamente
técnico aplicado ao
conhecimento profissional,
em que os professores
estão ausentes, já que se
convertem em um
instrumento isolado e
mecânico de aplicação e
reprodução, cujas
competências são apenas
de aplicação técnica.

Essa recontextualização promovida pelo trabalho coletivo não é fácil, pois o atual contexto profissional do professor, principalmente da educação básica, não comporta tempo para que ocorra o diálogo para gerar o trabalho coletivo. Muitas ações são pensadas em outros contextos e impostas aos docentes que se tornam meros executores, sem condição de poder pensar e discutir sobre as mesmas.

Após refletir sobre os quatro princípios pedagógicos do PIBID, continuamos a discussão sobre as bases epistemológicas do programa apresentando o desenho metodológico do Programa.

O desenho metodológico do PIBID

Conforme relatório CAPES/DEB (BRASIL,2015, p.66), “[...] o processo de 
modificação e (re)construção de uma nova cultura educacional que se pretende alcançar com o PIBID é pautado em pressupostos teórico-metodológicos, que articulam teoria- prática, universidade-escola e formadoresformandos". A figura a seguir apresenta o desenho metodológico do Programa:

Figura 02 - Desenho metodológico do PIBID

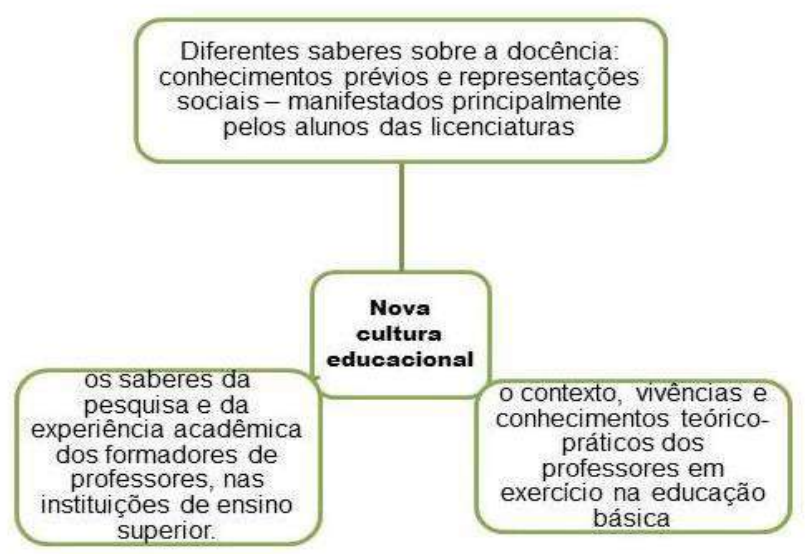

Fonte: Adaptado de CAPES/DEB ( 2015, p. 65).

Buscando criar e consolidar uma nova cultura educacional, o programa articula três diferentes ângulos da Formação: o do senso comum, dos saberes acadêmicos e do contexto escolar. Partindo da valorização dos conhecimentos prévios dos saberes culturais e entrelaçando-os com os saberes científicos, respeitando o contexto de cada lugar, é possível ultrapassar as barreiras ideológicas na formação docente que impõem determinados saberes como mais importantes.

$\mathrm{O}$ PIBID, quando promove $\mathrm{e}$ acompanha a inserção do licenciando na escola, juntamente com o professor da escola e da instituição formadora, tem uma proposta que permite preencher uma grande lacuna, que nem os estágios supervisionados, e nem as práticas pedagógicas presentes nas diretrizes dos cursos de licenciatura conseguiram ultrapassar: uma formação que não fica apenas na idealização, mas que observa, problematiza, reflete e busca intervenções que valorizam a reflexão-açãoreflexão (SCHÖN, 2000).

Quando um licenciando inicia o curso, muitas vezes, vai por falta de opção decorrente de inúmeros motivos. A oportunidade de vivenciar aspectos do lócus do trabalho docente proporciona o encontro ou o desencontro com a docência. Quando ocorre o encontro, percebe-se o PIBID como indutor $\mathrm{e}$ potencializador do percurso formativo.

Para sair do papel da mera reprodução da complexidade social e procurando romper modelos cristalizados, o PIBID, como Programa, fomenta por meio da interação entre a IES e a EB, a articulação gerada pelos diferentes saberes. Nesse sentido, Gatti (2014, p.42,43) assevera que é necessário " [...] criar condições concretas para um novo tipo de formação inicial, no ensino superior, para a docência na educação básica", a qual atinge de forma direta os professores que vão atuar nas escolas municipais e estaduais. É preciso para tanto, "[...] uma política nacional firme, com foco na qualidade formativa de novos professores para que ocorra a renovação educacional necessária ao país".

Muitas conquistas já foram efetivadas, mas ainda falta muito para que a realidade da formação e profissionalização docente seja tratada, nas políticas nacionais, de forma efetiva e que venha promover a valorização e o prestígio social do magistério. Para maior aprofundamento em relação ao programa, 
serão apresentados e discutidos os objetivos do mesmo.

\section{Os objetivos do PIBID na articulação da formação docente \\ O PIBID, ao lançar seus objetivos baseados em vertentes bem delineadas em}

seus princípios, contribui para uma formação articulada com a realidade a ser vivenciada e com a interação entre a instituição formadora e o lócus do trabalho docente. Conforme portaria $\mathrm{n}^{\circ}$ 096, de 18 de julho de 2013, são objetivos do PIBID.

\section{Quadro 01 - Objetivos do PIBID}

\section{OBJETIVOS DO PIBID}

I - incentivar a formação de docentes em nível superior para a educação básica;

II - contribuir para a valorização do magistério;

III - elevar a qualidade da formação inicial de professores nos cursos de licenciatura, promovendo a integração entre educação superior e educação básica;

IV - inserir os licenciandos no cotidiano de escolas da rede pública de educação, proporcionando-lhes oportunidades de criação e participação em experiências metodológicas, tecnológicas e práticas docentes de caráter inovador e interdisciplinar que busquem a superação de problemas identificados no processo de ensino/aprendizagem;

V- incentivar escolas públicas de educação básica, mobilizando seus professores como coformadores dos futuros docentes e tornando-as protagonistas nos processos de formação inicial para o magistério;

VI - contribuir para a articulação entre teoria e prática necessárias à formação dos docentes, elevando a qualidade das ações acadêmicas nos cursos de licenciatura;

VII - contribuir para que os estudantes de licenciatura se insiram na cultura escolar do magistério, por meio da apropriação e da reflexão sobre instrumentos, saberes e peculiaridades do trabalho docente.

Fonte: Adaptado de (BRASIL/CAPES, 2013).

Os objetivos que direcionam o Programa são observados na construção de cada projeto institucional nas IES, bem como dos seus respectivos subprojetos, cujas ações devem contemplar cada um dos mesmos. A seguir, cada objetivo será apresentado e discutido.

O objetivo de incentivar a formação de docentes em nível superior faz parte das políticas nacionais de formação para $o$ Magistério na educação básica.

Conforme os dados do INEP, publicados no Anuário da Educação (TODOS PELA EDUCAÇÃO, 2015, p. 102), do total de 2.148,023, professores na Educação Básica em 2013, aproximadamente um quarto não possui curso superior. No ensino fundamental, apenas $38,8 \%$ dos professores atuam na área específica da licenciatura, e, $48,3 \%$, no ensino médio.

Trazendo ainda um foco mais específico das licenciaturas, Gatti (2014, p.39), afirma que há uma "[...] ausência de integração formativa na direção de um perfil profissional de professor para atuar na educação básica", ou seja, a licenciatura não foca a formação para a atuação nas escolas de educação básica. Discute também a necessidade de rever a concepção tradicional de formação inicial de profissionais apenas como propedêutica desvinculada da experiência de trabalho.

A formação inicial é um dos passos da profissionalização do professor, a qual promove a implantação de uma política de melhoria da educação básica (MELLO, 2000). Essa formação precisa romper com algumas fragilidades, entre elas a prática pedagógica e as diferentes competências para o ensino de crianças, adolescentes, jovens e adultos. Essas lacunas na formação constatam a necessidade de melhor qualificar a formação inicial de professores para a educação básica, no entanto, a necessidade de criação de programas, sinaliza que as licenciaturas não estão oferecendo formação adequada aos futuros docentes (GATTI, 2014, p. 41). 
Com relação ao objetivo de contribuir para a valorização do magistério, é muito comum encontrar nas instituições de ensino, principalmente da educação básica, um quadro geral de insatisfação dos professores com a sua carreira. Fruto de um histórico de doação e vocação, o sentido de profissionalismo da carreira docente tem sido construído com muita luta sindical da categoria, tanto nacional quanto internacionalmente.

Essa valorização passa por fatores subjetivos das condições de reconhecimento social e prestigio, como também por fatores relativos ao exercício profissional, remuneração e condições de trabalho. Um dos fatores subjetivos é a questão de gênero: Baseado em dados do Anuário brasileiro de educação básica, o sexo feminino representa $80,29 \%$ do total de professores da educação básica, sendo o maior número nas séries iniciais do ensino fundamental, e o menor número no ensino médio. (TODOS PELA EDUCAÇÃO, 2015, p. 102 ).

Além de questões de gênero, existem várias relações contextuais envolvendo políticas públicas, contextos sociais, históricos e culturais. Uma delas se refere à falta de uma política nacional da carreira docente que ultrapasse as diferenciações entre professores federais, estaduais e municipais. Também as questões relacionadas ao rural e urbano, ao público e privado entre outras, reforçam aspectos que se tornam pontos de fragmentação das políticas em relação à carreira docente, o que favorece a desvalorização da mesma (SCHEIBE, 2010).

O fator socioeconômico também se mantém como elemento de desvalorização, identificado pelos baixos salários predominantes e a deterioração das condições de trabalho. Mesmo com muitas conquistas dos professores por meio das lutas sindicais da categoria, o salário docente ainda se configura como o mais baixo entre as demais categorias profissionais que exigem nível superior.

Tendo a valorização do Magistério como um dos seus objetivos, o PIBID contribui com a formação inicial para que o licenciando encare a docência com profissionalismo e perceba as relações complexas que envolvem a carreira.

Outro objetivo do programa é elevar a qualidade da formação inicial de professores nos cursos de licenciatura, promovendo a integração entre educação superior e educação básica.

Discutir a noção de qualidade torna-se complexo no sentido de conceber o que vem a ser qualidade da formação? Qual a noção de qualidade que a educação enfoca? Para Gadotti (2013), a qualidade da educação precisa ser encarada de forma sistêmica. A educação só pode melhorar no seu conjunto. A concepção de qualidade precisa evidenciar as questões sociais, políticas e a diversidade cultural. Qualidade não se mede só pela reprodução de conteúdos, mas também pela criação de conhecimentos que se conquistam pela pesquisa, pela leitura, pela reflexão.

Nessa discussão, Gatti, Barreto e André (2011 p.27), afirmam que

O Brasil ainda está distante
de uma qualidade
educacional considerada
razoável, sobretudo no que
se refere às redes públicas
de ensino, que atendem à
maioria das crianças e dos
jovens brasileiros. Vários
são os fatores
intervenientes nessa
situação, entre eles a
questão dos docentes, sua
formação e suas condições
de trabalho.

Assim sendo, o PIBID, nesse seu objetivo, precisa articular uma visão de formação inicial de qualidade que supere a concepção mercadológica de quantidade/qualidade e compreenda as várias dimensões presentes nessa formação, que envolve o atual contexto histórico com tantas e rápidas mudanças.

A qualidade da formação inicial dos professores passa pelos cursos de Licenciatura, os quais formam os professores para a educação básica nas etapas de: educação infantil; ensino fundamental; 
ensino médio. Necessitando de muitos enfrentamentos, entre eles o da baixa procura pelos jovens, as licenciaturas têm sido a única opção ou opção secundária para a maioria dos estudantes que ingressam nesses cursos nas IES, conforme dados do MEC/INEP - Censo da Educação Superior 2013.

Scheibe, (2010, p.5), contribui com a discussão, ressaltando que o cenário atual da valorização do magistério "[...] exige assumir prioridades para tornar a ocupação não apenas mais atrativa e valorizada, mas também mais competente para o desenvolvimento de uma educação com qualidade para todos".

Diante dessas multirreferencialidades e também dos problemas relacionados às aprendizagens escolares em uma sociedade cada dia mais complexa, cresce a preocupação com as licenciaturas, seja quanto às estruturas institucionais que as abrigam, seja quanto aos seus currículos e conteúdos formativos. (GATTI, 2010, p.1359).

Com um histórico de inferioridade em relação aos bacharelados, as licenciaturas precisam de uma imersão na pesquisa no enfoque da prática profissional e dos saberes docentes, para sair da contramão de formações aligeiradas, em direção a um comprometimento com a Pedagogia e a Didática, tanto quanto das especificidades das áreas.

Por meio das vivências nas escolas através do PIBID, muitos estudantes, que entraram na licenciatura como única opção ou opção secundária, aprendem a gostar da docência quando se sentem valorizados e reconhecidos pelos estudantes da educação básica, o que tem possibilitado a ressignificação da docência por meio dos sentidos atribuídos nessas vivências.

Nessa conjuntura, o PIBID trabalha os três aspectos da universidade: ensino, pesquisa e extensão, promovendo a integração entre educação superior e educação básica e fortalecendo a relação teoria/prática. Para Libâneo (2002), promover a integração da formação inicial com o lócus do trabalho docente é ter como referência e suporte a prática docente existente nas escolas, atendendo às necessidades da formação inicial, a partir das exigências da realidade na prática escolar cotidiana.

Inserir os licenciandos no cotidiano de escolas é outro importante objetivo do PIBID. Essa inserção, segundo Libâneo (2002, p.62), é importante para interligar o processo experiencial ao processo de aquisição do saber cientifico. Trabalhar com o cotidiano é lidar com um objeto de conhecimento, é investigar $\mathrm{o}$ real $\mathrm{e}$, portanto, implica $\mathrm{o}$ desenvolvimento do raciocínio, habilidades de pensamento, criação e inovação.

Cunha (2008), sinaliza alguns critérios e olhares sobre as experiências inovadoras: a ruptura com a forma tradicional de ensinar e aprender; gestão participativa; a reconfiguração dos saberes; a reorganização da relação teoria/prática; perspectiva orgânica no processo de concepção, desenvolvimento e avaliação da experiência desenvolvida; mediação; protagonismo. Nesse sentido,

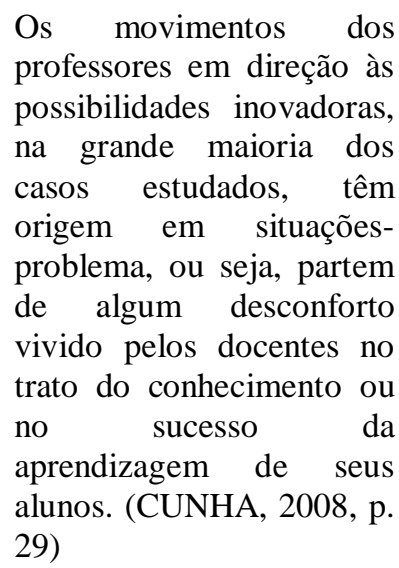

As situações vivenciadas pelos licenciados, durante as ações dos subprojetos, permitem, através da mediação dos professores e do protagonismo dos mesmos, a criação de novas ações pedagógicas que nem sempre necessitam de grandes investimentos, mas, principalmente, da reflexão na ação, da pesquisa e da prática pedagógica.

Outro objetivo do Programa, que é incentivar escolas públicas de educação básica, mobilizando seus professores como coformadores dos futuros docentes, toca numa área de importância fundamental para as mudanças na formação docente, pois as 
formações, distanciadas do seu lócus, criaram especialistas sem vivência e, consequentemente, fortaleceram a dicotomia teoria/prática.

Mobilizar os professores das escolas para o protagonismo na formação inicial é muito difícil, pois a lógica de receber os alunos como estagiários ainda é muito evidente, e os professores supervisores das escolas, na maioria, não conseguem se ver como coformadores. Segundo Nóvoa (2009), é preciso passar a formação de professores para "dentro" da profissão, isto é, basear-se na aquisição de uma cultura profissional, concedendo aos professores mais experientes um papel central na formação dos mais jovens. Para Gatti, (2010, p. 1375).

$$
\begin{aligned}
& \text { A formação de } \\
& \text { professores profissionais } \\
& \text { para a educação básica } \\
& \text { tem que partir de seu } \\
& \text { campo de prática e } \\
& \text { agregar a este os } \\
& \text { conhecimentos } \\
& \text { necessários selecionados } \\
& \text { como valorosos, em seus } \\
& \text { fundamentos e com as } \\
& \text { mediações didáticas } \\
& \text { necessárias, sobretudo } \\
& \text { por se tratar de formação } \\
& \text { para orabalho } \\
& \text { educacional com crianças } \\
& \text { e adolescentes. }
\end{aligned}
$$

Essa mobilização, que envolve os professores da educação básica como protagonistas da formação com base experiencial, é um determinante importante para motivar os docentes a continuar sua formação e autoformação.

Contribuir para a articulação entre teoria e prática é outro objetivo do PIBID, o qual articula todos os envolvidos numa dimensão de grande importância para mudanças.

Demo (2003, p. 77) diz que "[...] para as ciências sociais, uma teoria desligada da prática, não chega sequer a ser uma teoria", e que "nas outras ciências, a prática aparece extrínseca à teoria". O autor chama a atenção para a clássica visão positivista da ciência em geral e esclarece que "A teoria usa conceitos abstratos mesmo que os tenha retirado do concreto, porquanto não se põe a explicar situações concretas individuais, mas a regularidade do acontecimento concreto." (p.78). Com relação ao conceito de prática, assevera que "[...] a prática é sempre uma das aplicações possíveis da teoria. Nenhuma prática esgota a generalidade da teoria." (p.78).

Nesse raciocínio, mesmo que as teorias pedagógicas e de outras ciências, tenham seus princípios, haverá sempre um contexto específico de aplicação das mesmas em que diversos fatores estão entrelaçados os quais dependerão das intenções, convicções e interpretações. Nesse sentido, ainda no pensamento de Demo (2003, p.79)

Duas são as grandezas da
prática: de um lado, o teste
da realidade concreta,
através do rual
experimentamos r se
estamos diante de um
objeto construído ou de um
objeto inventado e
alienado; de outro, a
realização da coerência
ideológica, através da qual
cumprimos o que
pretendemos na teoria.

Para Pimenta (2012), o entendimento do conceito de prática tem diferentes conotações: prática como aquisição de experiência, prática como uma dissociação entre a formação e o campo de trabalho, no caso a escola. Percebe-se, assim, a interdependência entre teoria e prática e a constatação de que a articulação entre ambas é uma abordagem muito recorrente atualmente nos cursos em geral e principalmente nas licenciaturas, sendo parte das diretrizes nacionais, a prática pedagógica no decorrer de todo o curso. Para Libâneo, (2002, p. 28),

Teoria e prática são duas formas distintas de comportamento humano frente à realidade, mas indissoluvelmente ligadas 
na atividade consciente dos sujeitos [...] a prática docente é prática efetiva, ação consciente, pensada, nutrida pela teoria, mas que é prática.

Dentro da atuação do professor na sala de aula, é necessário mobilizar várias ações no sentido de realizar a dinâmica ensino/aprendizagem, sendo, portanto imprescindíveis a reflexão, o planejamento de estratégias, para que possam alcançar o objetivo do aluno aprender. Segundo Libâneo, (2012, p. 56).

\footnotetext{
Pela sua natureza, o trabalho educativo é um trabalho prático, entendendo "prático" no sentido de envolver uma ação intencional, pensada, dirigida a objetivos. $\mathrm{O}$ professor aprimora o seu trabalho apropriando-se de instrumentos de mediação desenvolvidos na experiência humana, que tornam mais efetivo $o$ ensino das matérias e a formação de ações mentais pelos alunos. Não se trata de tecnicismo, mas de relação entre a prática de ensino e o princípio teórico-científico que lhe dá suporte.
}

Mesmo sendo o trabalho educativo de natureza prática, ele não pode ser baseado no expontaneismo ou intuição; precisa de um suporte teórico que fundamente as suas ações.

Conforme Pimenta (2012, p. 95) "a atividade docente é práxis", partindo principalmente do pensamento de Marx, que defende a indissociabilidade entre teoria e prática.

A atividade teórica é que possibilita de modo indissociável $\quad 0$ conhecimento da realidade e o estabelecimento de finalidades para sua transformação. Mas, para produzir tal transformação, não é suficiente a atividade teórica; é preciso atuar praticamente (PIMENTA, 2012, p. 105).

Nesse sentido, é preciso um cuidado para não cair no "praticismo" prática pela prática dissociada da reflexão teórica, como também no "utilitarismo", busca pelos resultados imediatos, como adverte Pimenta (2012a, p. 105)

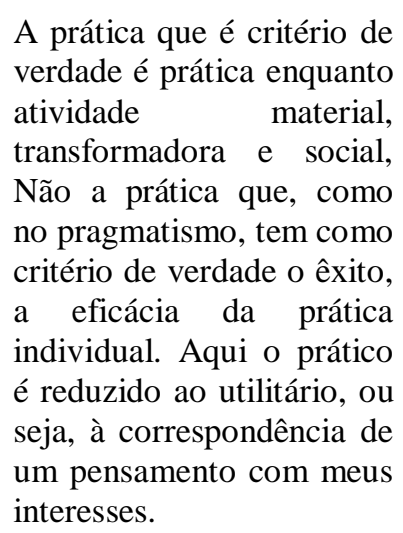

O PIBID parte do pressuposto de que a prática, por meio da inserção na escola, é o elemento articulador dessa relação, sendo assim, local de formação e produção de conhecimentos. Nesse sentido, a relação entre teoria e prática propriamente dita se efetiva na atividade profissional, mesmo não dispensando e não se dissociando da teoria.

O último objetivo do Programa destacado é contribuir para que os estudantes de licenciatura se insiram na cultura escolar do magistério. O PIBID, ao inserir o professor da escola pública, como coformador, permite uma valorização dos saberes experiências que, conforme Tardif (2014, p.39), “[...] incorporam-se à experiência individual ou coletiva sob a forma de habitus e de habilidades de saber-fazer e de saber-ser".

O termo hábitus é abordado por Bordieau (2007a, 2007b) e expressa um determinado sistema de disposições adquiridas consciente ou inconscientemente em determinado meio e sob determinadas condições, produto da interiorização das estruturas objetivas, que funciona como estratégia de reprodução. Para o autor, o hábitus representa capital cultural e recursos 
de poder e operacionaliza-se numa relação dialética entre a situação e o hábitus. Sendo assim, a cultura escolar docente influencia e também sofre a influência dos licenciandos na cotidianidade escolar.

Conforme Rodrigues (2012, p. 25), referindo-se ao fazer pedagógico e à docência, a relação com a prática cotidiana é questão importante na formação, no sentido de mediar os aspectos teóricos e as intenções e, também, ativar as capacidades contidas no hábitus, para executar atividades no exercício profissional.

As peculiaridades do fazer pedagógico evidenciadas no cotidiano docente por meio das ações do PIBID são compartilhadas com os licenciandos em formação, permitindo aos mesmos uma oportunidade de participar dos planejamentos, rotinas, modos de ensinar, experiências, dos professores das escolas que subsidiarão suas ações e reflexões. Ao mesmo tempo, os professores vivenciam com os licenciandos, inovações e desafios no fazer docente.

Baseados nos princípios, desenho metodológico e objetivos apresentados, o PIBID, como programa, estabeleceu-se de uma forma tão contundente que, em 4 de abril de 2013, a Lei 12.796, sancionada pela Presidenta da República, altera o texto da Lei de Diretrizes e Bases 9.394/96 para incluir, entre outras questões, no Art. $62, \S 5^{\circ}$, o incentivo ao magistério para atuar na educação básica por meio do PIBID. (BRASIL, 2013). Essa conquista, em 2013, já sofreu abalos na questão financeira em 2015, sofrendo cortes de bolsas e de verbas de custeio para o programa.

\section{Conclusão}

Refletir sobre a importância dos fundamentos epistemológicos do PIBID baseados nos seus princípios pedagógicos, desenho metodológico e objetivos, permite ter uma visão do programa em seus aspectos estruturantes que remetem às questões da profissionalização dos professores e aos desafios das políticas públicas de formação docente no país.

Permite também visualizar uma perspectiva nova para as licenciaturas, a qual possibilita a mobilização das mesmas para as abrangências de uma formação inicial mais articulada com a realidade do lócus profissional, como também uma formação continuada que corresponda as inquietações e desafios nas experiências dos professores.

As perspectivas que permeiam o programa na indução da profissão oportunizam vivências, e fortalecem as licenciaturas no sentido de sair do ideal pretendido para o vivido, refletido e avaliado, proporcionando experiências que promovem ressignificações na docência em relação às especificidades da profissão.

\section{Referências}

BOURDIEU. Pierre. Os três estados do capital cultural. (p.73-79). In: Escritos de Educação . 9.ed. Petrópolis, RJ: Vozes. 2007a.

Campo do poder, campo intelectual e hábitus de classes (p. 183-202). In: A economia das trocas simbólicas. São Paulo: Perspectiva, 2007b.

BRASIL. Decreto n. 7.219 de 25/06/2010. Dispõe sobre o Programa Institucional de Bolsa de Iniciação a Docência e dá outras providências. Disponível em: < http://www.planalto.gov.br/ccivil_03/_ato200 7-2010/2010/decreto/d7219.htm> Acesso em: jun. 2013.

BRASIL/CAPES. Portaria $n^{\circ}$ 096, de 18 de julho de 2013. Disponível em: http://www.capes.gov.br/images/stories/down load/legislacao/Portaria_096_18jul13_Aprova RegulamentoPIBID.pdf > Acesso em: jan. 2014.

CAPES/DEB. Relatório de Gestão 20092014. Vol. I. Brasília, 2015. Disponível em: 
$<$

http://www.capes.gov.br/images/stories/down load/bolsas/20150818_DEB-relatorio-degestao-vol-1-com-anexos.pdf >Acesso em: dez. 2015.

CUNHA, Maria Isabel da. Inovações pedagógicas: o desafio da reconfiguração de saberes na docência universitária. São Paulo: Cadernos de Pedagogia Universitária 6/USP, 2008.

Disponível

em:<

http://porteiras.r.unipampa.edu.br/portais/cap/ files/2010/10/maria_isabel_da_cunha_cadern o_VI.pdf> Acesso em: mai. 2014.

DEMO, Pedro. Pesquisa: princípio científico e educativo. 10. ed São Paulo: Cortez, 2003.

GADOTTI, Moacir. Qualidade na educação: uma nova abordagem . Florianópolis, 2013. disponível em: http://www.pmf.sc.gov.br/arquivos/arquivos/p df/14_02_2013_16.22.16.85d3681692786726 aa2c7daa4389040f.pdf > Acesso em: mar. 2015.

GATTI, Bernadete Angelina. Formação de Professores no Brasil: Características e Problemas. Educação e Sociedade. Campinas, v. 31, n. 113, p. 1355-1379, out. Dez. 2010, p. 1355 - 1379. Disponível em < http://www.scielo.br/pdf/es/v31n113/16.pdf>

Acesso em: abr. de 2014.

. Formação inicial de professores para a educação básica: as licenciaturas. Revista USP. São Paulo, n.100, p.33-46, dez./jan./fevereiro. 2013-2014. Disponível em: $<$

http://www.revistas.usp.br/revusp/article/view /76164/79909> Acesso em: nov. 2015.

. ; BARRETTO, Elba Siqueira de Sá ; ANDRÉ, Marli Eliza Dalmazo de Afonso. Políticas docentes no Brasil: um estado da arte. Brasília: UNESCO, 2011. Disponível em: http://unesdoc.unesco.org/images/0021/00212 1/212183por.pdf >Acesso em: nov. 2014.

IMBÉRNON, Francisco. Formação continuada de professores. Porto Alegre: Artmed, 2010.

LIBÂNEO, José Carlos. Ensinar e aprender, aprender e ensinar: o lugar da teoria e da prática em didática. In: LIBÂNEO, José Carlos e ALVES, Nilda ( orgs.) Temas de Pedagogia: diálogos entre didática e currículo. São Paulo: Cortez, 2012.

Adeus professor, adeus professora? Novas exigências educacionais e profissão docente. 6 ed. São Paulo: Cortez, 2002.

MEC/INEP. Censo de Educação Superior 2013. Disponível em: < http://download.inep.gov.br/educacao_superio r/censo_superior/apresentacao/2014/coletiva_ censo_superior_2013.pdf > Acesso em: ago. 2014.

MELO, Geovana Ferreira. Docência na universidade: em foco os formadores de professores. In: MELO, Geovana Ferreira. NAVES, Marisa Lomônoca de Paula. (orgs.) Didática e docência universitária. Uberlândia: EDUFU, 2012.

MELLO, Guiomar Namo de. Formação inicial de professores para a educação básica: uma (re)visão radical. São Paulo em Perspectiva, 14(1), p. 98-110, 2000. Disponível em: http://www.scielo.br/pdf/spp/v14n1/9807.pdf > Acesso em: dez. 2015.

NÓVOA, Antônio. Para uma formação de professores construída dentro da profissão. Revista Educacion. Madrid: 2009. Diasponível em:< http://www.revistaeducacion.educacion.es/re3 50/re350_09por.pdf> Acesso em: mai. 2014.

Novas disposições dos professores:

A escola como lugar da formação; Adaptação 
de uma conferência proferida no II Congresso de Educação do Marista de Salvador (Baía, Brasil), em Julho de 2003. Disponível em:, http://repositorio.ul.pt/bitstream/10451/685/1/ 21205_ce.pdf> Acesso em: jan. 2015.

PIMENTA, Selma Garrido. O estágio na formação de professores: unidade, teoria e prática? São Paulo: Cortez, 2012.

Professor reflexivo: construindo uma crítica. IN; PIMENTA, Selma Garrido. GHEDIN, Evandro (Orgs). Professor reflexivo no Brasil: gênese e crítica de um conceito. 7. ed. São Paulo: Cortez, 2012a.

RODRIGUES, José Roberto Gomes. Pedagogia e Ensino de História da Educação. Brasília: Liber Livro, 2012.

SCHEIBE, Leda. Valorização e formação dos professores para a educação básica: questões desafiadoras para um novo plano nacional de educação. Educação e Sociedade. Campinas, v. 31, n. 112, p. 981-1000, jul.-set. 2010. Disponível em <http://www.scielo.br/pdf/es/v31n112/17>Ac esso em: dez. 2015.

SCHÖN, Donald A. Educando o profissional reflexivo. São Paulo: Artmed, 2000.

TARDIF, Maurice. Saberes docentes e formação profissional. 17. ed. Rio de Janeiro, Petrópolis: Vozes, 2014.

TODOS PELA EDUCAÇÃO. Anuário brasileiro de educação básica 2015. São Paulo: Moderna. Disponível em:< http://www.todospelaeducacao.org.br/bibliote ca/conteudo-tpe/1515/anuario-brasileiro-daeducacao-basica-2015/> Acesso em: ago.2015. 